\title{
The Finnish Diabetes Risk Score (FINDRISC) and increased body weight
}

\author{
Joanna Pekar', Rafał Mazur', Małgorzata Kozilewicz', Aleksandra Jóźwiak', Anna Olszewska², \\ Katarzyna Skórzyńska-Dziduszko ${ }^{2}$
}

'Students' Scientific Association at the Chair and Department of Human Physiology, Medical University of Lublin, Poland
2 Chair and Department of Human Physiology, Medical University of Lublin, Poland

\begin{abstract}
Introduction. The Finnish Diabetes Risk Score (FINDRISC) assesses the 10-year type 2 diabetes risk in adults by identifying individuals with overweight or obesity, inadequate physical activity, poor nutrition, or a family or personal history of hyperglycaemia.

Aim. The objective of the study was to analyse the effect of FINDRISC components, particularly overweight/ obesity, on the total FINDRISC score of randomly selected individuals.

Material and methods. The study was conducted in 2015 on 91 individuals - 45 women and 46 men. We determined FINDRISC score and measured blood pressure twice. The results were analysed in STATISTICA 10 at $\mathrm{p}<0.05$.

Results. Thirty subjects (32.97\%) were overweight (BMI 25-29.9 kg/m²) and $12(13.19 \%)$ were obese (BMI $\left.>=30 \mathrm{~kg} / \mathrm{m}^{2}\right) ; 25(27.47 \%)$ had high waist circumference (M: 94-102 cm; F: 80-88 cm) and $24(26.37 \%)$ abdominal obesity (M: > $102 \mathrm{~cm}$; F: > $88 \mathrm{~cm}$ ). Individuals with overweight/obesity, high waist circumference or abdominal obesity had significantly higher FINDRISC scores than those with normal body weight and waist circumference. Obese individuals showed a strong tendency $(p=0.06)$ towards higher FINDRISC scores than overweight individuals, but no similar difference was noted between high waist circumference and abdominal obesity. Overweight and obese subjects had significantly higher blood pressure, but with no difference between them. Individuals with abdominal obesity, but not those with high waist circumference, had significantly higher blood pressure.

Conclusions. Diabetes risk is increased by high waist circumference, but does not continue to increase with waist circumference, whereas in the case of BMI the risk gradually increases. BMI influences blood pressure more than waist circumference does.
\end{abstract}

Keywords: overweight, obesity, waist circumference, FINDRISC.

\section{Introduction}

Type 2 diabetes is a progressive condition in which the body becomes resistant to the normal effects of insulin and/or gradually loses the capacity to produce insulin.

The number of patients with type 2 diabetes is continuously rising. The International Diabetes Federation (IDF) publishes a yearly report on the incidence of dia- betes worldwide and in individual countries. The most recent report indicates that 415 million people suffered from diabetes worldwide in 2015 , including $6.2 \%$ of the population in Poland [1].

The risk factors for type 2 diabetes include overweight and obesity. The problem of obesity affects all segments of society. According to the Central Statistical Office of Poland, in 2009 about 36.4\% of the 
Polish population was overweight and $15.8 \%$ were obese. This problem is beginning to affect people at an increasingly early age, including children and teenagers [2].

The Finnish Diabetes Risk Score (FINDRISC) questionnaire is a screening tool used to estimate the 10-year risk of type 2 diabetes in adults.

The scale is used to identify individuals with the following risk factors of diabetes: age, overweight or obesity, a low level of physical activity, poor nutrition, a family or personal history of hyperglycaemia, or use of anti-hypertensive medication. FINDRISC consists of eight questions about these risk factors. Every question gives a score in relation to how much it predicts the risk of T2DM. The total score from the questionnaire predicts the future risk for T2DM within 10 years. The maximum score possible to get is 26. Identification by FINDRISC of high-risk individuals can be followed by educational intervention, which has been shown to reduce the incidence of diabetes and prevent the development of complications of this disease $[3,4]$.

Since the FINDRISC score includes both the body mass index and waist circumference to evaluate the type 2 diabetes risk, an interesting question arises as to how strongly these factors may affect FINDRISC score.

The objective of the study was to analyse the effect of FINDRISC components, particularly overweight/ obesity, on the total FINDRISC score of randomly selected individuals.

\section{Material and methods}

The study was carried out in 2015 by medical students during the $12^{\text {th }}$ Lublin Science Festival on a group of 91 individuals - 45 women (F) and 46 men (M). Participation in the study was voluntary and anonymous. The participants were selected randomly. Participants were divided according to gender, BMI and waist circumference. The FINDRISC score was determined for the subjects and their blood pressure (BP) was measured twice. A risk score from 0 to 7 indicates a low risk of type 2 diabetes (an estimated 1 in 100 individuals in this group will develop diabetes within 10 years); 7-11 indicates a slightly increased risk (about 1 in 25 will develop diabetes within 10 years); $12-14$ a moderate risk ( 1 in 6 individuals), and 15-20 a high risk (1 in 3). When the score exceeds 20 , the risk is considered to be very high (an estimated 1 of every 2 people in this group will develop type 2 diabetes within 10 years) [5]. The values for the parameters analysed were presented as arithmetic mean, standard deviation, minimum and maximum values, lower and upper quartiles, and median. The Shapiro-Wilk test was used to assess the normality of distribution of parameters, the chi-squared test to determine whether there was a significant difference between the expected frequencies and the observed frequencies in categorical data categories, and the Kruskal-Wallis $\mathrm{H}$ test to compare the type of distribution and variance homogeneity between more than two groups. A significant Kruskal-Wallis $\mathrm{H}$ test was followed by the Dunn-Bonferroni post hoc method, which was used to compare the difference in the sum of ranks between columns with the expected average difference. A $p$ value of less than 0.05 was considered statistically significant. The data were analysed using STATISTICA 10.0 software (StatSoft, USA). All procedures involving participants were approved by the local Research Ethics Committee (KE-0254/71/2011).

\section{Results}

Thirty subjects (32.97\%) were found to be overweight (BMI 25-29.9 kg/m²) and 12 (13.19\%) were obese $\left(\mathrm{BMI}>=30 \mathrm{~kg} / \mathrm{m}^{2}\right)$. High waist circumference (M: 94-102 cm; F: $80-88 \mathrm{~cm}$ ) was noted in 25 $(27.47 \%)$ subjects and abdominal obesity ( $\mathrm{M}>102$ $\mathrm{cm} ; \mathrm{F}>88 \mathrm{~cm})$ in $24(26.37 \%)$.

Individuals with abdominal obesity were statistically significantly older (the Kruskal-Wallis $\mathrm{H}$ test, $\mathrm{p}<0.05$ ). In the case of BMI no statistically significant relationship with age was observed, although BMI showed a tendency to increase with age (the Kruskal-Wallis $\mathrm{H}$ test, $\mathrm{p}=0.08$ ).

Obese individuals showed a tendency (the Kruskal-Wallis $\mathrm{H}$ test, $\mathrm{p}=0.06$ ) towards higher FINDRISC scores than overweight individuals (Figure 1).

In terms of the FINDRISC score no statistically significant difference was found between subjects with high waist circumference and those with abdominal obesity (Figure 2).

Among individuals with normal BMI there were four with abdominal obesity, whereas all obese subjects also had abdominal obesity.

Subjects with BMI > $30 \mathrm{~kg} / \mathrm{m}^{2}$ statistically significantly more often reported taking antihypertensive drugs than respondents with lower BMI (the chi-squared test, $p<0.05$ ), but this association was not found in the case of individuals with high waist circumference. When the 29 individuals that declared taking 


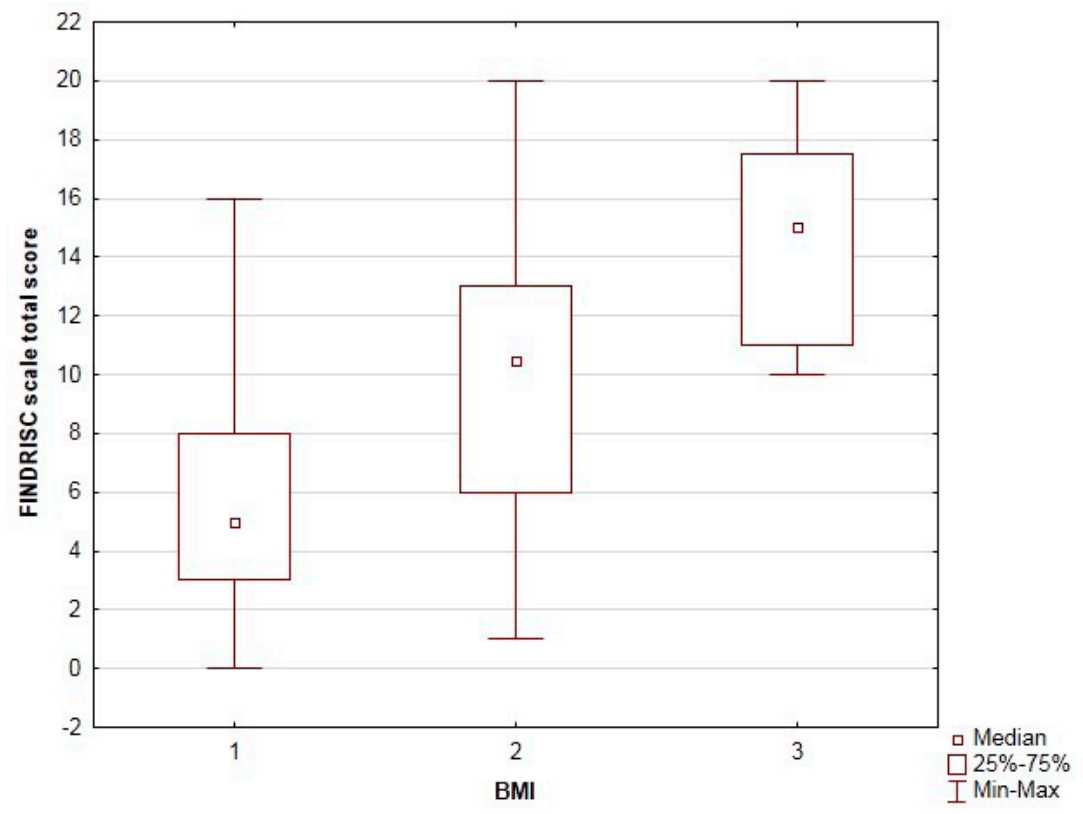

Figure 1. FINDRISC score in subjects with normal BMI $<25 \mathrm{~kg} / \mathrm{m}^{2}$ (1), overweight subjects - BMI 25-29.9 $\mathrm{kg} / \mathrm{m}^{2}(2)$ and obese subjects $-\mathrm{BMI}>=30 \mathrm{~kg} / \mathrm{m}^{2}(3)$

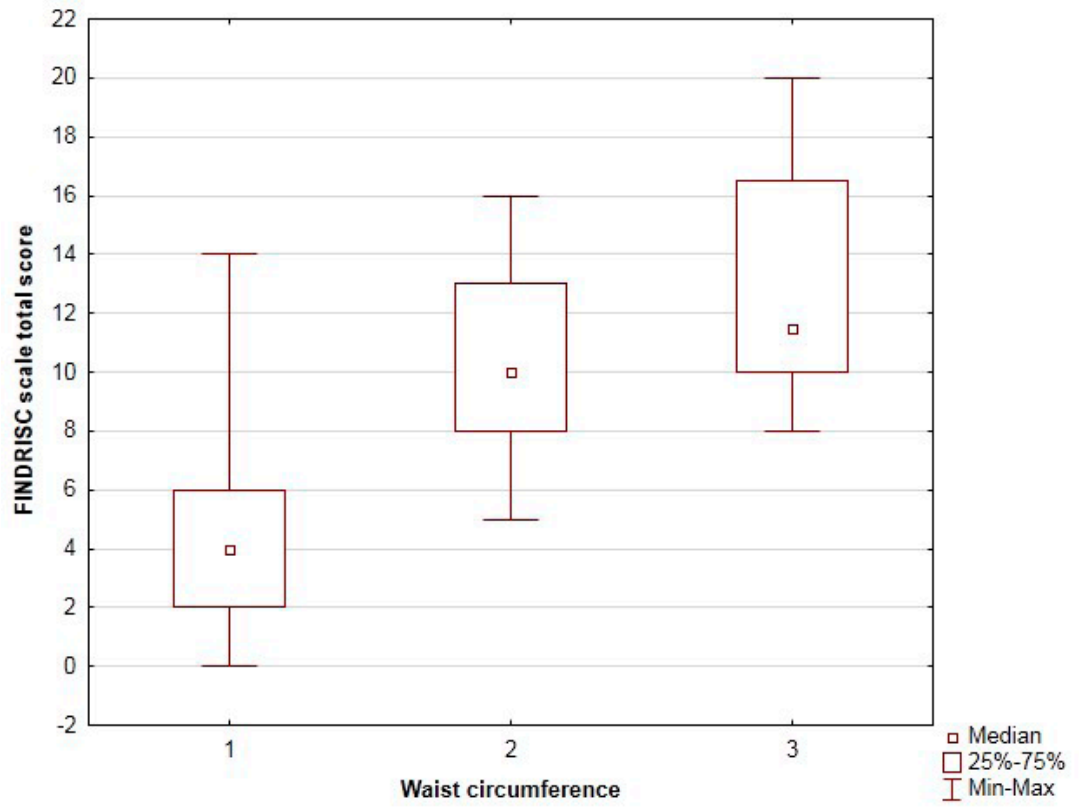

Figure 2. FINDRISC score in subjects with normal waist circumference $-\mathrm{M}<94 \mathrm{~cm}, \mathrm{~K}<80 \mathrm{~cm}(1)$, high waist circumference- M: 94-102 cm; F: 80-88 cm (2) and abdominal obesity - M > $102 \mathrm{~cm}$; F $>88 \mathrm{~cm}$ (3)

antihypertensive drugs were excluded from the statistical analysis, systolic and diastolic blood pressure were found to be significantly higher in overweight or obese individuals than in those with normal body weight (the Kruskal-Wallis $\mathrm{H}$ test, $\mathrm{p}<0.05$ ) (Figure 3 ). However, no difference in blood pressure was noted between overweight and obese individuals.

Interestingly, a significant increase in systolic and diastolic blood pressure was noted in individuals with 
A

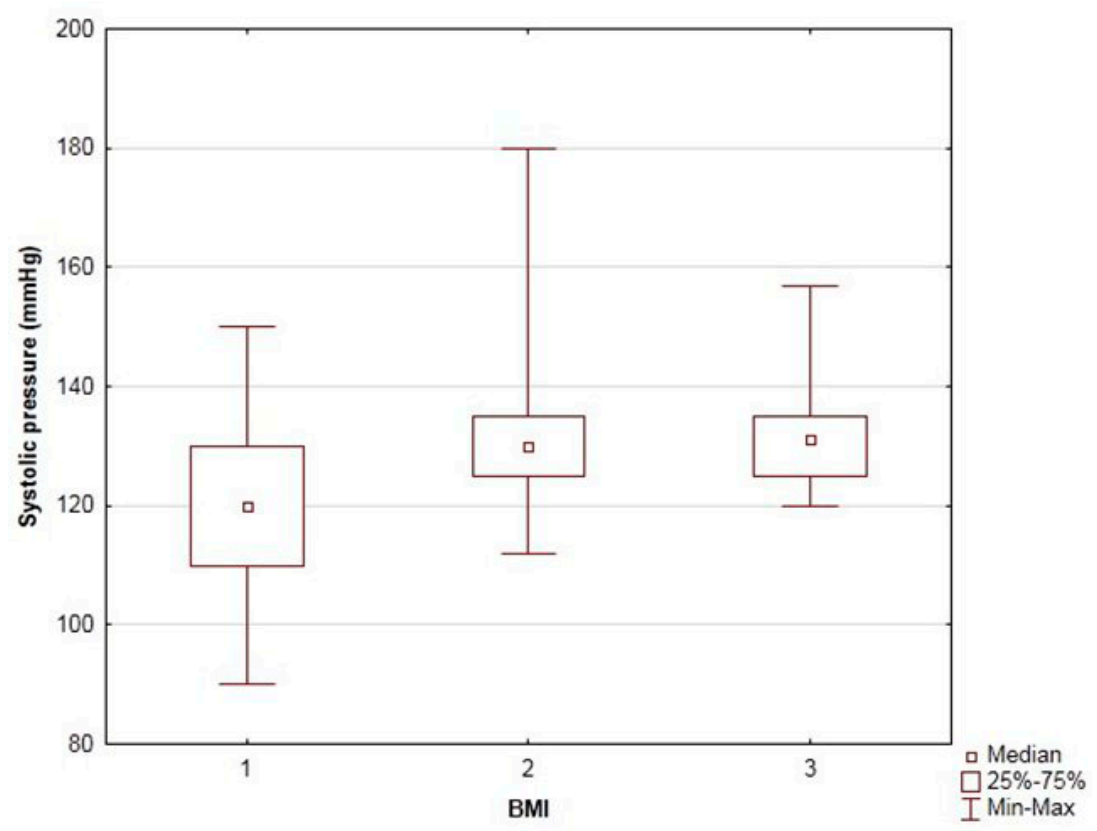

B

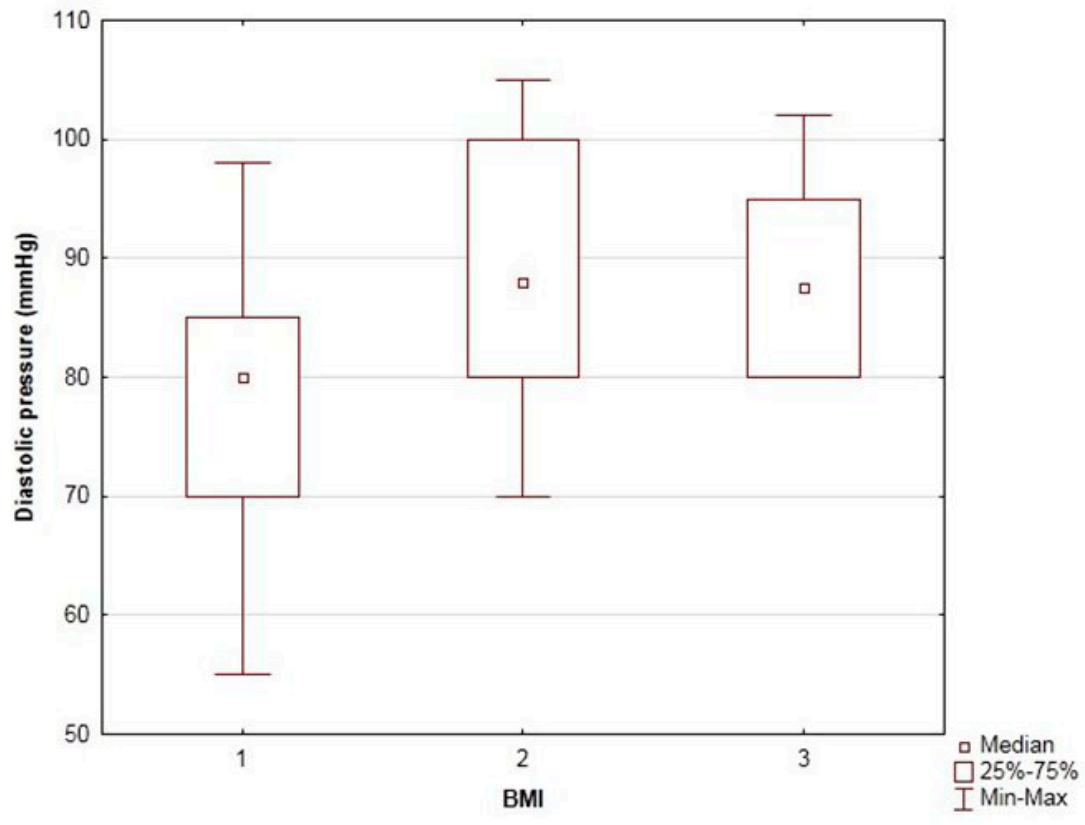

Figure 3. Systolic (A) and diastolic (B) blood pressure in subjects with normal BMI (1), overweight subjects (2) and obese subjects (3)

abdominal obesity (the Kruskal-Wallis $\mathrm{H}$ test, $\mathrm{p}<0.05$ ), but not in those with moderately high waist circumference (Figure 4).

Respondents with abdominal obesity reported a low level of physical activity statistically more frequently (the chi-squared test, $p<0.05$ ), but no difference in physical activity was observed between slim individuals and those with elevated BMI. Obese individuals statistically more often reported eating less fruit and vegetables than those with normal body weight (the chi-squared test, $p<0.05$ ).

Surprisingly, no differences were noted between individuals with normal body weight or waist circumference and those with excessive body weight in terms of history of hyperglycaemia or diabetes in the family. 
A

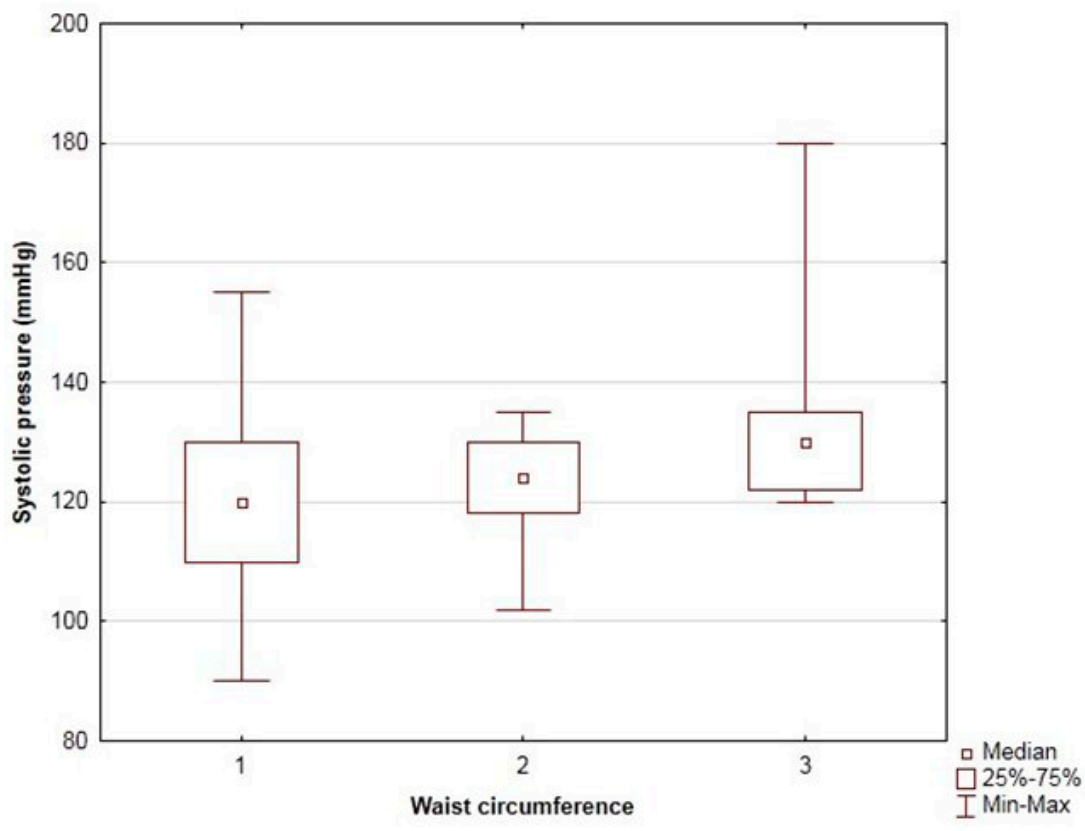

B

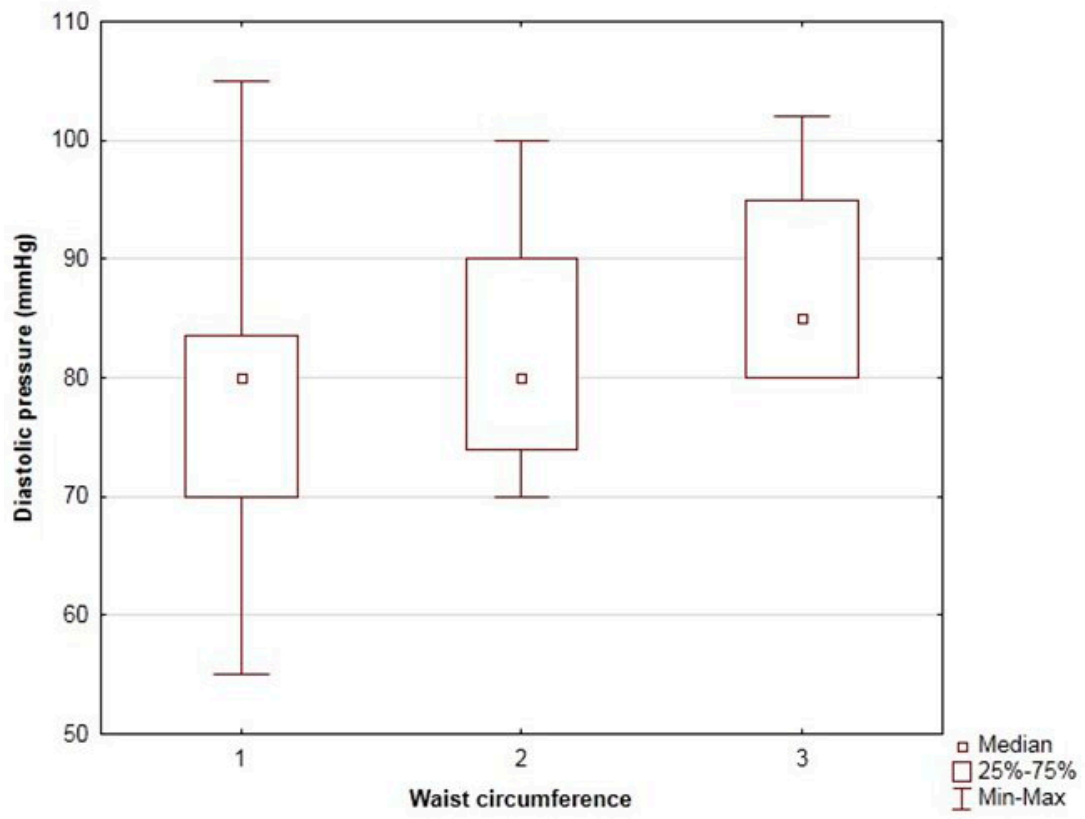

Figure 4. Systolic (A) and diastolic (B) blood pressure in subjects with normal waist circumference (1), high waist circumference (2) and abdominal obesity (3)

\section{Discussion}

People attending the $12^{\text {th }}$ Lublin Science Festival were recruited for the study. Among these were relatively few individuals with $\mathrm{BMI}>30 \mathrm{~kg} / \mathrm{m}^{2}$ (12 people). It seems likely that obese individuals preferred to stay at home [6] or chose not to participate in the study because they anticipated unfavourable results [7]. It has been demonstrated that obese individuals struggle in society with feelings of guilt or shame because of their weight, and are often unable to cope with these problems [8]. Patients with obesity have also frequently mental disorders [9]. This suggests the 
need for a broad public initiative making it possible to reach these people and to take prophylactic and therapeutic measures to help them.

Our study shows that even individuals with a high FINDRISC score surprisingly seldom report a history of elevated blood glucose levels. One may speculate that these patients, were not regularly tested in the past and therefore they might have remained undiagnosed with hyperglycaemia. Government programmes to promote health and prevention by introducing regular obligatory glycaemia tests should play a greater role in preventing a further increase in the incidence of type 2 diabetes [10].

A family history of diabetes was also reported by few respondents. This could be explained both by a lack of knowledge of type 2 diabetes and by the growing problem of new cases of diabetes, or the increasing risk of this disease in individuals from previously healthy families [1].

The risk of diabetes and hypertension increases with BMI [11]. Interestingly, our results suggest that while high waist circumference raises the FINDRISC score, this does not continue to increase with a further increase in waist circumference. In contrast, increasing $\mathrm{BMI}$ is accompanied by a gradual increase in the FINDRISC score.

Our study also showed that obesity defined in terms of BMI did not fully correspond with obesity recognized on the basis of waist circumference. Other authors confirm these results, particularly in the case of women [12]. These data indicate that measurement of waist circumference is a somewhat better tool for identifying individuals with excess body weight than BMI.

Our study also showed that it is primarily waist circumference that increases with age, while BMI increases to a much lesser degree.

Another interesting observation is that BMI has a greater effect than waist circumference on blood pressure. This is confirmed by a study that showed that BMI is a more sensitive indicator of hypertension, whereas waist circumference is a better indicator of dyslipidaemia and diabetes [13]. Moreover, due to these differences WS Lee has recently proposed new algorithms defining the level of obesity in individuals [14].

\section{Perspectives}

High waist circumference raises the FINDRISC score, but the FINDRISC score does not continue to increase with waist circumference, whereas increasing BMI is accompanied by a gradual increase in the FINDRISC score. BMI has a stronger effect than waist circumference on blood pressure. General practitioners should encourage testing in patients and test all overweight and obese patients for development of type 2 diabetes. A public programme encouraging these individuals to undergo prophylactic examinations is necessary. On the other hand, nearly half of the respondents had normal BMI, which may be indicative of the growing awareness of the effect of an unhealthy lifestyle on the development of type 2 diabetes.

\section{Acknowledgements}

\section{Conflict of interest statement}

The authors declare no conflict of interest.

\section{Funding sources}

There are no sources of funding to declare.

\section{References}

1. International Diabetes Federation. IDF Diabetes Atlas, $7^{\text {th }}$ edition. 2015. International Diabetes Federation. 2015 [cited 17.02.2016]. Available at: http://www.idf.org/diabetesatlas.

2. Główny Urząd Statystyczny. Stan zdrowia ludności Polski w 2009 r. Zakład Wydawnictw Statystycznych, Warszawa 2011; 166-171 [cited 17.02.2016]. Available at: http:// stat.gov.pl/obszary-tematyczne/zdrowie/zdrowie/stan-zdrowia-ludnosci-polski-w-2009-r,6,5.html.

3. Leszczyk M. Skala oceny ryzyka wystąpienia zachorowania na cukrzycę typu 2 - FINDRIS. Kardiologia na co Dzień. 2009;4(3-4):103-104.

4. Lindstrom J, Tuomilehto J. The diabetes risk score: a practical tool to predict type 2 diabetes risk. Diabetes Care. 2003;26:725-731.

5. Rydén L, Standl E, Bartnik M, Van den Berghe G, Betteridge J, de Boer MJ, et al. Guidelines on diabetes, pre-diabetes, and cardiovascular diseases: executive summary. The Task Force on Diabetes and Cardiovascular Diseases of the European Society of Cardiology (ESC) and of the European Association for the Study of Diabetes (EASD). Eur Heart J. 2007;28(1):88-136.

6. Vincent HK, Lamb KM, Day TI, Tillman SM, Vincent KR, George SZ. Morbid obesity is associated with fear of movement and lower quality of life in patients with knee pain-related diagnoses. PM R. 2010 Aug;2(8):713-722.

7. Hearon BA, Quatromoni PA, Mascoop JL, Otto MW. The role of anxiety sensitivity in daily physical activity and eating behavior. Eat Behav. 2014 Apr;15(2):255-8.

8. Malterud K, Ulriksen K. Norwegians fear fatness more than anything else - a qualitative study of normative newspaper messages on obesity and health. Patient Educ Couns. 2010;81(1):47-52.

9. Pietrzykowska M, Nowicka-Sauer K, Cwaliński T et al. Mental disorders among persons with obesity. Fam Med Prim Care Rev. 2014;16(2):146-147.

10. Kurpas D, Kern JB, Jacquet JP, Randall-Smith J, Mroczek B. Programs of health promotion and disease prevention 
- examples from Europe and the US. Fam Med Prim Care Rev. 2015;17(2):152-156.

11. Mandal A. Study of prevalence of type 2 diabetes mellitus and hypertension in overweight and obese people. J Family Med Prim Care. 2014;3(1):25-28.

12. Freedman DS, Ford ES. Are the recent secular increases in the waist circumference of adults independent of changes in BMI? Am J Clin Nutr. 2015;101(3):425-431.

13. Zeng $Q$, He Y, Dong S, Zhao X, Chen Z, Song Z et al. Optimal cut-off values of BMI, waist circumference and waist: height ratio for defining obesity in Chinese adults. Br J Nutr. 2014;112(10):1735-1744.

14. Lee WS. Body fatness charts based on BMI and waist circumference. Obesity (Silver Spring). 2016;24(1):245-249.
Correspondence address:

Joanna Pekar

Students' Scientific Association at the Chair and Department of Human Physiology Medical University of Lublin,

11 Radziwillowska St, 20-080 Lublin, Poland phone: +48783549595 email: asia9384@o2.pl

Acceptance for editing: 2016-06-29

Acceptance for publication: 2016-06-30 